\title{
Design and Sizing Electric Micro Generator Using Thermoelectric Modules
}

\author{
Oswaldo Hideo Ando Junior ${ }^{1,2}$, Jesiel da Luz Ferro ${ }^{1}$ and Lírio Schaeffer ${ }^{2}$ \\ 1. Department of Electrical Engineering, Beneficent Association of Santa Catarina Coal Industry (SATC), Criciúma-Sc, Brazil \\ 2. School of Engineering, Federal University of Rio Grande do Sul (UFRGS), Porto Alegre-Rs, Brazil
}

Received: July 09, 2013 / Accepted: September 02, 2013 / Published: December 31, 2013.

\begin{abstract}
This paper presents the development of a methodology for calculating sizing electric micro sources of power generation using TEG (thermoelectric modules) to capture energy industrial process waste. Since the thermoelectric modules are able to convert a temperature gradient directly into electricity and still occupy a small space, and have no vibration or noise during operation. Furthermore, the cogeneration using thermoelectric modules is totally clean and reuses part of the residual thermal energy to generate power, or improve the overall yield of the process and avoid the emission of gases to the environment. Therefore, this research contributes to the development of a green energy to numerical modeling for the design and dimensioning of micro-sources of electric power generation from performance curves and predetermined temperature gradients industrial processes. The result is an effective methodology for the design and conditioning the voltage level and power of micro allowing the size of the electrical quickly and securely for many industrial applications, varying the types of modules used area, voltage and power generated.
\end{abstract}

Key words: Energy harvest, cogeneration system, green energy, thermoelectricity.

\section{Introduction}

With technological development and concern about global warming, the search for new sources of electricity generation denominated green energy [1].

Currently, people live in an energy crisis that has shown the limits of supply of energy to meet the energy demand [2].

In view of this, the energy issue has become vital for all countries of the world, and are extremely important to reduce dependence on fossil fuels, which today is the most widely used form of generation. Therefore, one should increasingly seek new ways of converting energy from alternative sources that are environmentally sustainable solutions to diversify the global energy matrix, thereby minimizing the overall environmental impacts, prioritizing renewable sources [3].

Corresponding author: Oswaldo Hideo Ando Junior, teacher, research fields: energy harvesting, green energy, energy conversion, power quality and power system. E-mail: oswaldo.junior@satc.edu.br.

\section{Methodology of Calculation}

This chapter begins presented the steps for designing a cogeneration system thermoelectric power, followed by details of each design phase.

\subsection{Cogeneration System for Thermoelectric Energy Harvesting}

The system consists of thermoelectric modules that convert heat energy into electrical energy. However, the system throughput is not only a function of thermoelectric modules, since the power output thereof depends on the temperature gradient. Therefore, the temperatures that the modules are subjected, has direct influence on total system performance.

To raise the output voltage of the system is possible to connect several modules in series and to raise the higher current may be connected in parallel several modules. It is noteworthy that only you can make arrangements with modules with the same internal 
resistance, otherwise will generate a potential difference between modules and therefore a current flow between the modules causing losses.

Due to changes in temperature thermal processes, the output voltage of the modules also varies applied to them for this reason that it is necessary to use a DC-DC converter to maintain constant tension on the load.

The impedance of the load in turn, will also influence performance in the power transfer, since the maximum energy transfer is obtained when the impedance matching is, i.e., when the internal electrical resistance of the proposed system is equal to electrical resistance of the load. Fig. 1 presents the block diagram showing the main steps for the construction and application of a generic thermoelectric cogeneration system harvesting energy.

In this system, the authors have as a heat source heat losses arising from processes that can be captured by surface contact systems, heat pipes and fins. The cold source is in a heat transfer system comprising: sinks, coils, cooling blocks and radiators.

The thermal system should be set according to the characteristics of the site to install the proposed system, in order to maximize the use of available resources in place to be implemented. It should be used as much thermal paste to the hot face in order to improve the thermal performance, as the cold face of the thermoelectric modules, to reduce the thermal resistance, as well as all other mechanical contacts in the system. It is also necessary to make a thermal insulation

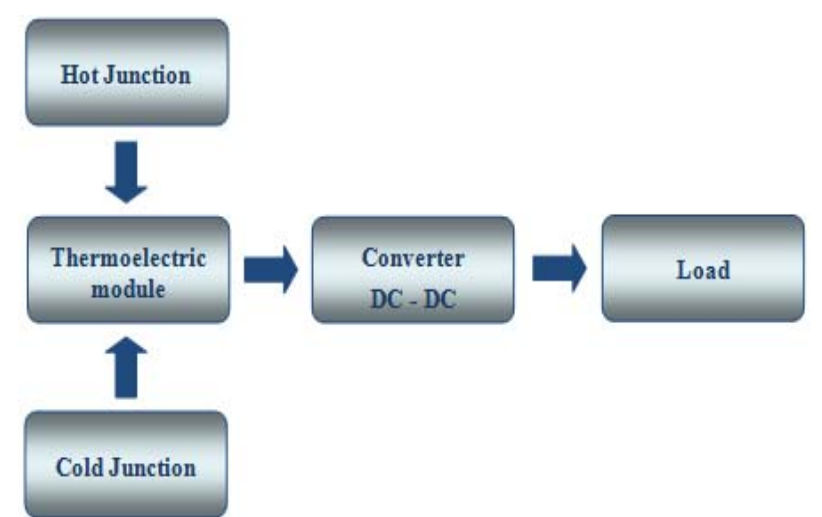

Fig. 1 Statement from the block diagram of the thermoelectric cogeneration system. between the two faces of the thermoelectric modules to prevent heat transfer by radiation, thereby maintaining the temperature difference higher.

For the determination of modules and their respective electrical arrangements must consider the necessity for the load to be supplied, and especially to analyze the performance curves of thermoelectric modules according to the temperature gradient obtained by the thermal transfer system. The characteristics curves with information related to the voltage and current output as a function of temperature difference are included in the datasheets of thermoelectric modules.

\subsection{Electrical Dimensioning of a Thermoelectric Cogeneration System}

This chapter presents the methodology of calculation developed to perform electrical design of the main components that are part of the cogeneration thermal power, which are:

- thermoelectric modules;

- DC-DC converters;

- batteries and cables.

For application of the methodology, it requires prior knowledge of the thermal performance of the system in place where it will be deployed and operating condition of the load to be fed. Therefore, the input data are:

- power supply voltage and load;

- temperature and temperature gradient font hot and cold;

- number of hours per day that the system is in operation;

- select the module and thermoelectric performance curve.

In order to ensure the development of best configuration of thermoelectric cogeneration system for a specific application, one should design the system with thermoelectric modules that have different characteristics (performance curves and dimensions) and choose the designed system that best meets the needs of implantation site. 


\subsection{Demand Forecasting Electricity Thermoelectric Cogeneration System}

The prediction of the energy consumed in thermoelectric system is the starting point for the design of any proposed system. This is the estimated daily consumption in Watt/hour, since not all systems are connected all day. A list of the rating of each load which will be used as well as the number of hours that the load will be in operation must be made in order to calculate the energy consumed by the load [4]. The calculation is done by Eq. (1):

$$
P_{\text {Consumida }}=P_{\text {Carga }} \cdot N_{\text {horas }}(\mathrm{Wh})
$$

where:

$P_{\text {Consumida: }}$ total energy consumption (Wh);

$P_{\text {Carga }}$ : load power (W);

$N_{\text {horas }}$ : number of hours of operation of the system (h).

\subsection{Estimation of the Current Load}

With the value of load power and the effective voltage required to power it is possible to calculate the load current $\left(I_{\text {Carga }}\right)$. This can be obtained using Eq. (2). It is noteworthy that this estimate of the load current ( $I_{\text {Carga }}$, will also be used to scale the DC-DC converter needed to keep the voltage constant at the desired value.

$$
I_{\text {Carg } a}=\frac{P_{\text {arga }}}{V_{\text {Carg } a}}(\mathrm{~A})
$$

where:

$P_{\text {Carga }}$ load power (W);

$V_{\text {Carga }}$ : supply voltage load (V).

2.5 Estimation of the Amount of Thermoelectric Modules

The number of modules required for the cogeneration system is directly dependent on the power and the load voltage and the temperature gradient of the thermal system, since the power generated is directly proportional to the temperature gradient. The definition of the thermoelectric module also enters this stage, because each model of thermoelectric module has different dimensions and curves of voltage, current and power specific to each model.

Determined after the load current $\left(I_{\text {Carga }}\right)$, one should choose the thermoelectric module to be used in the project and then analyze your datasheet to check which the arrangement of thermoelectric modules needed to meet the voltage and load current. To perform this analysis is used as the reference temperature gradient and the thermal system performance curves of the chosen modules.

In Fig. 2, the authors present the performance curves of voltage, current and power due to the temperature gradient removed from the thermoelectric module datasheet inbC1-127.08HTS [5].

There sheets that instead of providing the difference in temperature, the temperatures have the hot side and cold, as can be seen in Fig. 3 [6].

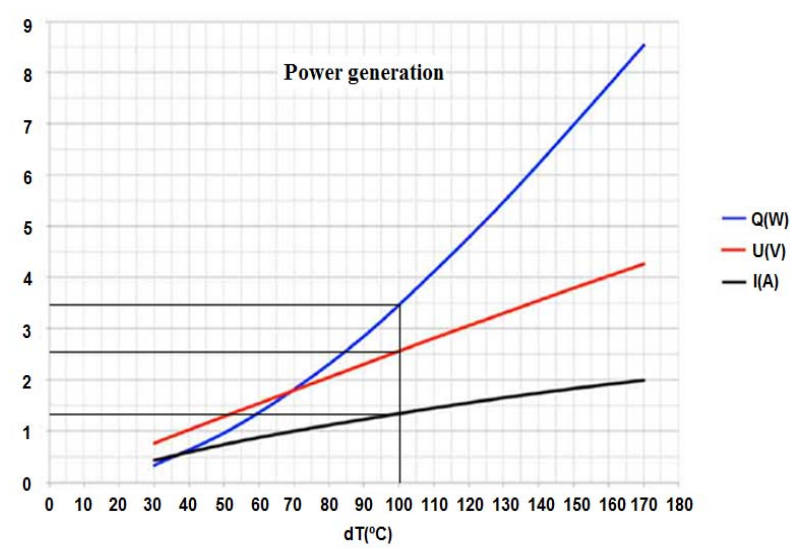

Fig. 2 Performance curves of voltage, current and power due to the temperature gradient [5].

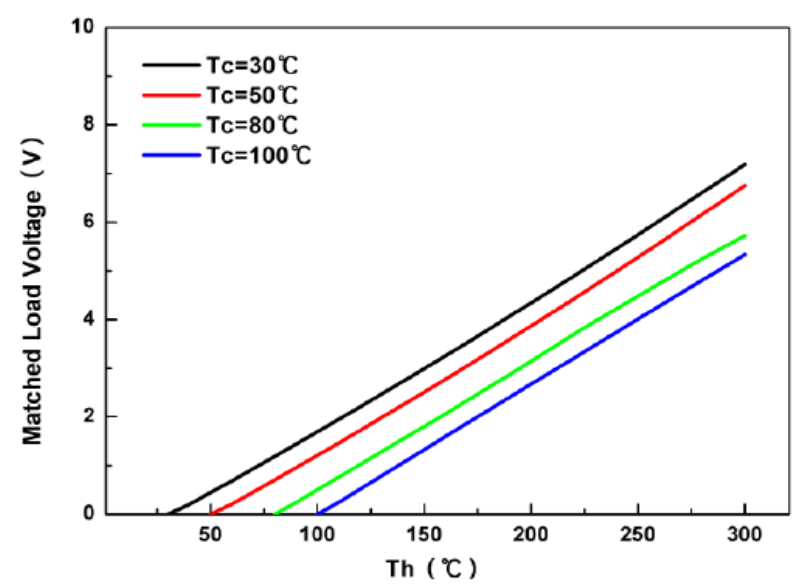

Fig. 3 Performance curve voltage generated in function of the temperatures of the hot side and cold [6]. 
Fig. 3 shows the performance curve of the voltage generated for only four temperatures on the cold side. If the temperature (Cold Spring) of operation of the system to be design differs from the temperatures used to obtain the curves, it should make an approximation of the values generated by interpolation using Eq. (3).

$$
\frac{T f_{\text {Sup }}-T f_{\text {Inf }}}{V_{\text {Sup }}-V_{\text {Inf }}}=\frac{T f_{\text {Sup }}-T f_{\text {mod }}}{V_{\text {Sup }}-V_{\text {mod }}}
$$

where:

$T f_{\text {Superior: }}$ : temperature of Cold Spring superior contained in the performance curve $\left({ }^{\circ} \mathrm{C}\right)$;

$T f_{\text {Inferior: }}$ : temperature of Cold Spring lower contained in the performance curve $\left({ }^{\circ} \mathrm{C}\right)$;

$T f_{\text {mod }}$ : temperature in Cold Spring this module $\left({ }^{\circ} \mathrm{C}\right)$;

$V_{\text {Superior: }}$ voltage generated for $T f_{\text {superior }}(\mathrm{V})$;

$V_{\text {Inferior: }}$ voltage generated for $T f_{\text {Inferior }}(\mathrm{V})$;

$V_{\text {mod }}$ : voltage generated for $T f_{\text {mod }}(\mathrm{V})$.

Preferably, one should choose $T f_{\text {Superior }}$ and $T f_{\text {Inferior }}$ in the condition that it is between $T f_{\text {mod }}$ these values chosen. In case $T f_{\text {mod }}$ is $70^{\circ} \mathrm{C}$, so it has to be $T f_{\text {Superior }} 80$ ${ }^{\circ} \mathrm{C}$ and $T f_{\text {Inferior }} 50^{\circ} \mathrm{C}$. Whereas $T f_{\text {mod }}$ is equivalent to $120{ }^{\circ} \mathrm{C}$ that is used $T f_{\text {Superior }} 100{ }^{\circ} \mathrm{C}$ and $T f_{\text {Inferior }} 80^{\circ} \mathrm{C}$. The interpolation method of Eq. (3) is also suitable for determining the current or power output based on performance curves, provided it is done the necessary changes.

2.6 Association Arrangement Series Thermoelectric Modules

To prove that the output voltage of the thermoelectric modules connected in series is equivalent to the sum of the individual voltage of each module underwent four modules of the same type (TEP1-1264-1.5) at the same temperature hot and cold side thereof. Thus, it is apparent that each module generated approximately the same output voltage and connecting another module in series with the first voltage has doubled. Placing the third and fourth module also connected in series with two voltage tripled and quadrupled compared to the voltage of only one module. Once obtained the voltage generated by thermoelectric module and the voltage value of the average power DC-DC converter system, it is possible to estimate the number of modules to be connected in series $\left(N_{\text {Series }}\right)$, knowing that the tension of each will be plus. Therefore, the number of modules in function of the voltage is obtained using Eq. (4).

$$
N_{\text {Serie }} \geq \frac{\Delta V_{\text {Conv }}}{V_{\text {mod }}} \Rightarrow \Delta V_{\text {Conv }}=\frac{V_{\text {max }}+V_{\text {min }}}{2}
$$

where:

$\Delta V_{\text {Conv }}$ : average voltage in DC-DC converter $(\mathrm{V})$;

$V_{\text {mod }}$ : generated module voltage $(\mathrm{V})$.

It is noteworthy that the voltage to power the converter must be found by the average between the maximum and minimum input, so if the input voltage of the DC-DC converter is $10 \mathrm{~V}$ to $20 \mathrm{~V} \Delta V_{\text {Conv }}$ the value will be equal to $15 \mathrm{~V}$. This should be done for safety reasons, since the output voltage of the modules varies continuously with the temperature gradient, which may exceed the maximum or minimum value of the supply voltage of the DC-DC converter. The value found is not always full, if that number is odd should always round it up or down in order to ensure greater operating range of the working voltage of the DC-DC converter.

\subsection{Parallel Arrangement of the Association of Thermoelectric Modules}

To prove that the current divides between modules connected in parallel, was fed a load with just a thermoelectric module and measured the current flowing in the module. Subsequently, another module was placed in parallel to the same specification module that has fed the load in order to verify that the current splits in parallel to two sources. Thus, the current of the module that was already in place is reduced by half, proving that the current splits with thermoelectric modules operating as voltage sources in parallel. Placing a third module in parallel to the other two, the current was reduced by a third, and a fourth module current divided into four parts.

Knowing the load current is how many blocks will 
be necessary associate series in parallel $\left(N_{\text {Paralelo }}\right)$ to supply the load current. Therefore, the number of modules that must be associated in parallel to supply the maximum current required by the DC-DC converter $\left(I_{\text {Critica }}\right)$ is obtained using Eq. (5).

$$
N_{\text {Paralelo }} \geq \frac{I_{\text {Critica }}}{I_{\text {mod }}} \Rightarrow I_{\text {Critica }}=I_{\text {Carga }} \cdot\left(\frac{V_{\text {Carga }}}{V_{\text {min }}}\right)
$$

where:

$I_{\text {Crítica: }}$ maximum current circuit (A);

$I_{\text {mod }}$ : current provided by a module (A).

As in the calculation based on the voltage value found is not always full. In this case, it is necessary to always round up the number found, because the value of the current modules support must be greater than the current system, to ensure proper functioning. If the number of modules found to be 3.9 modules, suggested to use 4 modules for a total guarantee, as the system temperature changes, also changing the value of the maximum current of the modules. If blocks are placed parallel modules further, there is no problem, since the number of blocks in parallel will not change the voltage but the current capacity supplied, as a security module if a burn but will burden the cost of project.

\subsection{Arrangement Electrical System Conversion Thermoelectric}

With the number of series and parallel association of thermoelectric modules duly pre-determined one can estimate the total number of modules required to perform the electrical arrangement of the thermoelectric conversion system $\left(N_{\text {mod }}\right)$ using the following Eq. (6).

$$
N_{\text {mod }}=N_{\text {Serie }} \cdot N_{\text {Paralelo }}
$$

where:

$N_{\text {Serie }}$ : number of thermoelectric modules in series;

$N_{\text {Paralelo: }}$ number of thermoelectric modules in parallel.

\subsection{Estimation of Minimum Area Occupied}

The minimum area (Area) occupied by the thermoelectric system can be obtained depending on the size of the thermoelectric module and the number of modules required to construct the electrical arrangement of the thermoelectric converter. Therefore, the area can be calculated by Eq. (7).

$$
\text { Area }=\operatorname{Larg} \times \text { Comp } \times N_{\text {mod }}\left(\mathrm{mm}^{2}\right)
$$

where:

Larg: width of the module in use (mm);

Comp: length of the module used (mm);

$N_{\text {mod }}$ : number of modules electrical arrangement of thermoelectric conversion system.

\subsection{Dimensioning of the DC-DC Converter}

In the design of the DC-DC converter its necessary having some values depending on the system characteristics, such as Ref. [7]:

- power supply to the load;

- maximum load connected to the converter;

- minimum voltage input DC-DC converter;

- maximum input voltage of the DC-DC converter.

In the design of the converter it should be set the values of Ref. [7]:

- switching frequency of the transistor;

- ripple current in the inductor (\%);

- output voltage ripple (\%).

The process of defining the type of DC-DC converter more suited to the proposed cogeneration system, consider the output voltage of thermoelectric modules that will feed the input of the DC-DC converter and the output voltage of the DC-DC converter that will feed the load.

If the input voltage is lower than the output voltage of the converter, the converter being used is to be the boost, since it raises the output voltage. Then, for an input voltage greater than the output, the converter must be of type buck, which has the function of lowering the output voltage.

A better analysis, should be a relationship between the power converter output $(\mathrm{Po})$ and the power consumed by the switching elements $(P t)$, neglecting the current ripple (the converter will work in continuous conduction mode) and the voltage ripple and assuming that the input voltage may vary as well as the duty cycle should be controlled to maintain the 
output voltage constant. Fig. 4 shows the relationship between the aforementioned power which is the index of use of switching elements with cycle [7].

It is observed that for voltages of the same magnitude buck converter is the one with better efficiency in the use of the switching elements, because the value for the duty cycle $(D)$ is close to unity 1 . Already the buck-boost converter has a low utilization rate, and the maximum value is $25 \%$ if the duty cycle is 0.5 . The great advantage of the buck-boost converter is able to operate at lower voltages and to higher output, as well as it fits the needs of the system, since the thermoelectric modules vary according to the temperature difference. For the design of any physical model chosen converter, it is suggested to use the sources: Barbi [7], Mendonça [8], Lima [9] and Seguel [10].

\subsection{Dimensioning Storage System}

The storage system is proposed for this work which is a battery, since the same option to serve as intermittent systems. It is noteworthy that the system can work without storage systems directly feeding the DC-DC converter. The battery must be sized to store the energy consumed daily and some days booking functioning as an emergency system in the absence of generation [4]. The battery capacity can be calculated by the following Eq. (8).

$$
Q_{\text {bat }}=\frac{P_{\text {Consumida }} \cdot N_{\text {dias }}}{V_{\text {Carg } a} \cdot t_{\max }}
$$

where:

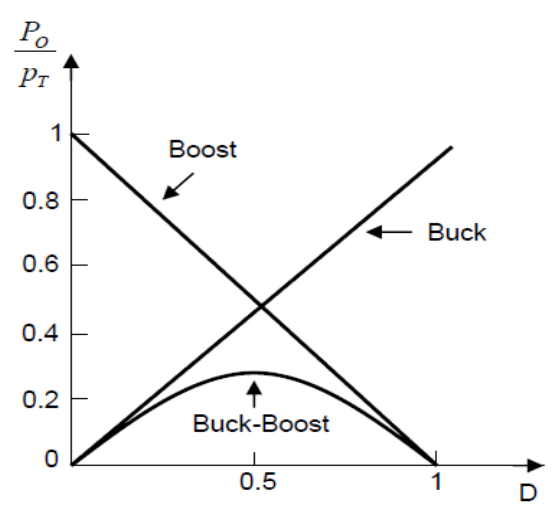

Fig. 4 Use of energy in DC-DC converters [7].
$P_{\text {Consumida: }}$ total energy consumption per day $(\mathrm{Wh})$;

$N_{\text {dias }}$ : number of days of autonomy;

$V_{\text {Carga: }}$ : the load voltage $(\mathrm{V})$;

$t_{\text {max }}$ : maximum allowed depth of battery charge $(0.3$ to 0.9$)$ [4].

\section{Estimated by Area Cogeneration}

In order to demonstrate the applicability of the developed methodology, this chapter will apply the methodology demonstrated in Chapter 2 to scale thermoelectric cogeneration system by capturing residual energies, applied to a power plant. The site chosen for capturing the heat input is the electrostatic precipitator, whose operation has a temperature of $215.5^{\circ} \mathrm{C}$ and hence to the cold side which has been evaporated at a temperature of $85^{\circ} \mathrm{C}$.

The system to be scaled aims to supply a load of 500 $\mathrm{W}$ with a voltage of $15 \mathrm{~V}$. Therefore, the current drawn by the load is $33.33 \mathrm{~A}$. The DC-DC converter to be used requires an input voltage of $10 \mathrm{~V}$ to $32 \mathrm{~V}$ to get into your $15 \mathrm{~V}$ outlet and the thermoelectric modules to be used are the type TEHP1-24156-1. Based on the performance curve of the voltage (Fig. 5) the module datasheet TEHP1-1.2-24156, are the values of the output voltage from each module depending on the hot and cold temperatures.

When analyzing Fig. 5, it can be seen that there is the exact value of the cold source temperature of $60{ }^{\circ} \mathrm{C}$, then it will be necessary to do interpolation. The curves are closer to $50{ }^{\circ} \mathrm{C}$ and $80{ }^{\circ} \mathrm{C}$, then will be chosen.

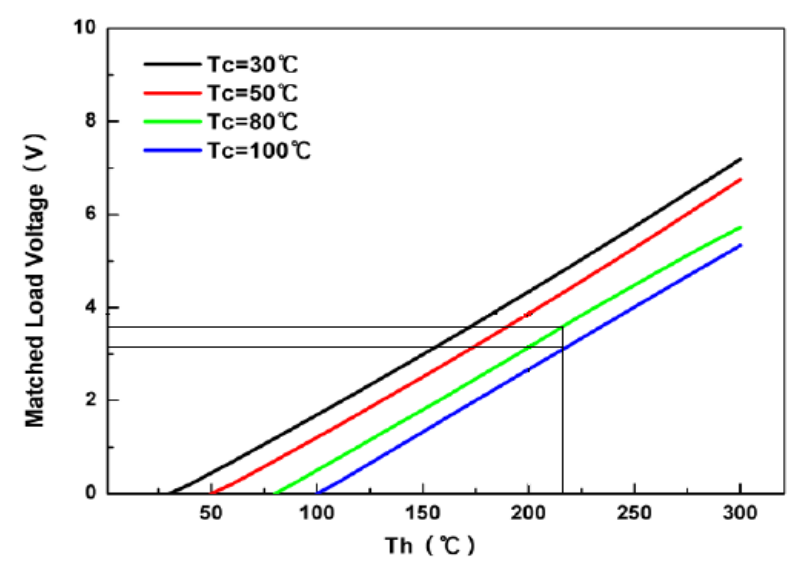

Fig. 5 Performance curve voltage under load module. 
Voltage values for each curve are $3.1 \mathrm{~V}$ and $3.9 \mathrm{~V}$, respectively. With this, all the values needed for interpolation are already known and to perform the interpolation uses Eq. (3).

$$
\begin{aligned}
& \frac{T f_{\text {Sup }}-T f_{\text {Inf }}}{V_{\text {Sup }}-V_{\text {Inf }}}=\frac{T f_{\text {Sup }}-T f_{\text {mod }}}{V_{\text {Sup }}-V_{\text {mod }}} \Rightarrow \frac{100-80}{3.7-3.1}=\frac{100-85}{3.7-V_{\text {mod }}} \Rightarrow \text { (9) } \\
& V_{\text {mod }}=3.25 \mathrm{~V}
\end{aligned}
$$

With the calculation, the value of the output voltage of each module is $3.25 \mathrm{~V}$. This value is applied to find the required number of modules in series. The DC-DC converter can be supplied with a voltage of $10 \mathrm{~V}$ to $32 \mathrm{~V}$. Therefore, the calculations will use the average voltage of the DC-DC converter and Eq. (4) to determine the number of modules connected in series:

$$
\begin{aligned}
& \Delta V_{\text {Conv }}=\frac{V_{\text {max }}+\Delta V_{\text {min }}}{2}=\frac{32+10}{2}=21 \mathrm{~V} \Rightarrow \\
& N_{\text {Serie }}=\frac{\Delta V_{\text {Conv }}}{V_{\text {mod }}}=\frac{21}{3.25}=6.46 \text { mod ules }
\end{aligned}
$$

As the number of modules was fractional, it will be a rounding and verification. In this case, it will be rounded up to 7 modules. The output voltage will be the product of the number of modules Eq. (6) and the same output voltage $(3.25 \mathrm{~V})$ totaling $22.75 \mathrm{~V}$. It was concluded that this number of modules fits the desired value. In the graph of current (Fig. 6), it is seen that with only one module is obtained $1.25 \mathrm{~A}$, and applying Eq. (5) can determine the number of associated modules in parallel:

$$
\begin{aligned}
& I_{\text {Critica }}=I_{\text {Carga }} \cdot\left(\frac{V_{\text {Carga }}}{V_{\text {min }}}\right)=33.33 \cdot\left(\frac{15}{10}\right)=50 \mathrm{~A} \Rightarrow \\
& N_{\text {Paralelo }} \geq \frac{50}{1.20}=41.66 \text { mod ules }
\end{aligned}
$$

So you should use 42 modules in parallel to the current which is greater than the critical current of $50 \mathrm{~A}$ system which is the minimum requirement. However, maximum current with 42 modules of $50.4 \mathrm{~A}$ is operating in the temperature gradient design.

The total number of system modules is found using Eq. (6).

$$
N_{\text {mod }}=N_{\text {Serie }} \cdot N_{\text {Paralelo }}=7 \times 42=294 \text { mod ules }
$$

The minimum area occupied by the thermoelectric system can be calculated by Eq. (7).

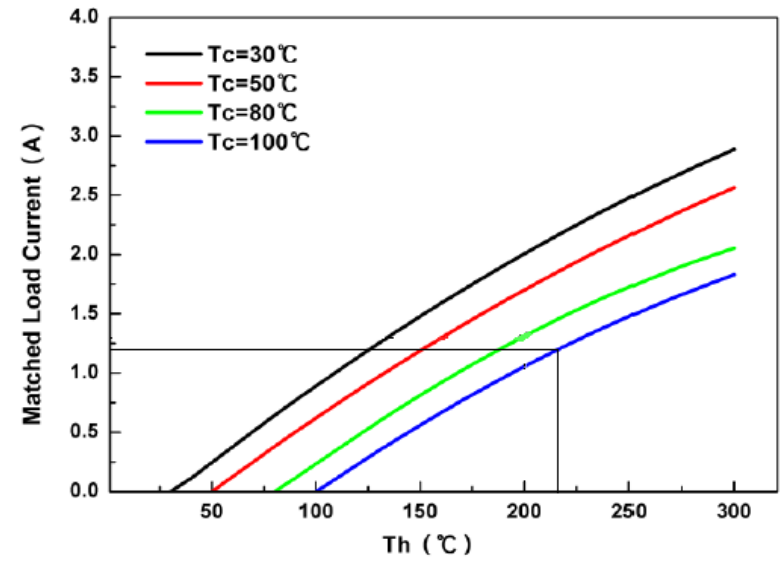

Fig. 6 Performance curve current load module.

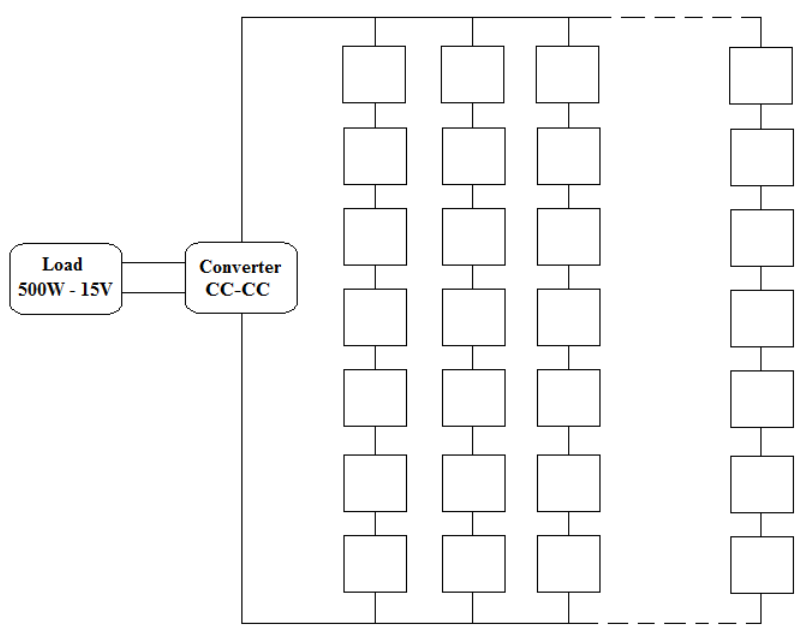

Fig. 7 Statement of the electrical arrangement of thermoelectric converter.

Area $=$ Larg $\cdot$ Comp $\cdot N_{\text {mod }}=0.0565 \times 0.0565 \times 294 \cong 0.938 \mathrm{~m}^{2}(13)$

Fig. 7 shows how the arrangement will be electric thermoelectric converter containing the links of thermoelectric modules connected in series and parallel.

\section{Conclusions}

The results of the sizing system based on preliminary experimental tests without using the hybrid system of this heat transfer in progress. With the data obtained, it is also important to highlight the need to raise the performance curve of the model of the selected module to different temperature gradients, to validate the information the datasheet. The number of modules required to implement the micro generator directly the temperature gradient and the efficiency of heat transfer 
from the cold joint. In the modeled system with reduced cold junction temperature of $85{ }^{\circ} \mathrm{C}$ to $70{ }^{\circ} \mathrm{C}$ has improved performance models of about $20 \%$, which corresponds a reduction of thermoelectric modules 54 .

Ends up emphasizing the need for research to develop materials to facilitate the use of cogeneration systems by improving the energy conversion efficiency and reduce the cost for developing a national technology topology adapted to the application site. The prototyping and development of a thermoelectric micro generator in industrial scale is also important for studying new ways to make arrangements with combinations of thermal and electrical to maximize the efficiency of the cogeneration system and thereby reduce costs and volume. Moreover, it emphasizes the need to search for new topologies for heat transfer systems that allows for the increase of the temperature gradient and consequently improving the system performance thermoelectric cogeneration.

\section{References}

[1] S.A.M. Bastos, Bracelet for power generation, Master Thesis, University of Minho, Braga, 2010.
[2] L.P. Santos, Performance analysis of a thermoelectric generator based on the Seebeck effect, Master Thesis, University of Taubaté, Taubaté, 2010.

[3] J.A.A. Antunes, Reuse of heat to electric power generation in automotive, Master Thesis, University of Minho, Braga, 2011.

[4] S.S.A. Freitas, Design of photovoltaic systems, Master Thesis, Polytechnic Institute of Bragança, Bragança, 2008.

[5] Datasheet inbC1-127.08HTS thermoelectric power generation [Online], http://www.inbthermoelectric.com/Thermoelectric-Peltier -Modules/Power-Generators/inbC1-127.08HTS.html (accessed Apr. 28, 2013).

[6] Datasheet specification of thermoelectric module TEHP1-24156-1.2 [Online], http://www.thermonamic.com/TEHP1-24156-1.2.pdf (accessed Jan. 28, 2013).

[7] I. Barbi, Power Electronics, in: S.C. Florianópolis (Ed.), Santa Catarina, Brasil, 2005.

[8] R.C. Mendonça, Design of DC-DC Converters Basic non Insulated, Scientific Research, State University of West Paraná, Foz do Iguaçu, 2002.

[9] A.S. Lima, Comparison of two boost converters for application in battery chargers, a standalone photovoltaic system applying principles of value engineering, Master Thesis, Federal University of Ceará, Fortaleza, 2008.

[10] J.I.L. Seguel, Design of a photovoltaic system autonomous power supply using technique and MPPT control digital, Master Thesis, Federal University of Minas Gerais, Belo Horizonte, 2009. 